Supplement of Atmos. Chem. Phys., 22, 1811-1824, 2022

https://doi.org/10.5194/acp-22-1811-2022-supplement

(C) Author(s) 2022. CC BY 4.0 License.

(c) (1)

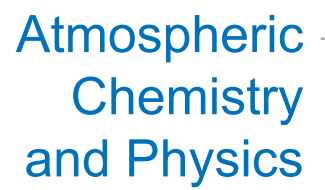

Supplement of

\title{
Reproducing Arctic springtime tropospheric ozone and mercury depletion events in an outdoor mesocosm sea ice facility
}

\section{Zhiyuan Gao et al.}

Correspondence to: Feiyue Wang (feiyue.wang@umanitoba.ca)

The copyright of individual parts of the supplement might differ from the article licence. 


\section{Text S1. NO $\mathrm{N}_{\mathrm{x}}$ chemistry on ozone loss within the in-tube air}

In this experiment, we studied the ozone loss $\left(\Delta \mathrm{O}_{3}\right)$ by comparing between different locations (the ambient air vs. in-tube air; the UV-transmitting tube vs. UV-blocking tube). For $\Delta \mathrm{O}_{3}$ within the in-tube air (the ambient air vs. in-tube air), the ambient air can be considered as a control group while the in-tube air is the experimental group that examines the influence from sea ice and acrylic tube. Since the tube was open to the ambient environment, we consider similar air mass for both the ambient air and in-tube air, including $\mathrm{NO}_{\mathrm{x}}$ from urban signal that was already present in the background ambient air. This assumption is also supported by overall similar $\mathrm{O}_{3}$ trends observed between the ambient air and in-tube air (see Fig. 3 and Fig. S4). In this case, NO titration (mainly produced from urban signal) would equally affect $\mathrm{O}_{3}$ dynamics in the ambient air and in-tube air, which is an offset process when studying $\Delta \mathrm{O}_{3}$ via the comparison between the ambient air and intube air. Thus, such $\Delta \mathrm{O}_{3}$ should not be affected by variations of $\mathrm{NO}_{\mathrm{x}}$ in the background ambient air. Since the $\Delta \mathrm{O}_{3}$ within the in-tube air examines the influence from sea ice, $\mathrm{NO}_{\mathrm{x}}$ production via snowpack photochemistry may be important, yet this process is considered negligible due to the low concentrations of nitrite and nitrate found in surface ice and saline snow samples. Then, $\mathrm{NO}_{\mathrm{x}}$ that may influence $\mathrm{O}_{3}$ dynamics is only expected from urban signal (the background ambient air) and should have little influence on the $\Delta \mathrm{O}_{3}$ within the in-tube air. We believe our general assumption that variations of $\mathrm{NO}_{\mathrm{x}}$ in the background ambient air do not affect $\Delta \mathrm{O}_{3}$ obtained from comparisons is sound.

The assumption that the air mass between the ambient air and in-tube air was similar is challenged when there was a sudden and rapid disturbance (e.g., occasional use of vehicles within the facility). In this case, the vehicle exhaust signal was readily captured in the ambient air while the in-tube air was less affected due to a lack of rapid air mixing. During daytime, $\mathrm{O}_{3}$ can be produced from photochemical oxidation of hydrocarbons in the vehicle exhaust or $\mathrm{NO}_{2}$ photochemistry. This increased $\mathrm{O}_{3}$ signal (within 20 minutes from the vehicle use) could be immediately observed as a lesser extent of $\mathrm{O}_{3}$ depletion in the ambient air at the beginning of the disturbance, whereas such $\mathrm{O}_{3}$ increase was not necessarily captured in the in-tube air due to a lack of rapid air mixing. This condition would overestimate $\Delta \mathrm{O}_{3}$ and result in those abnormal high values out of the general $\Delta \mathrm{O}_{3}$ trend observed around 12:00 on 6 and 9 March (shaded areas in Fig. $\mathrm{S} 4)$. NO produced from on-site use of vehicles could subsequently cause small-scale $\mathrm{O}_{3}$ depletion in both the ambient air and in-tube air. However, during each day, the $\Delta \mathrm{O}_{3}$ was observed before 
the sharp increase of $\mathrm{NO}_{\mathrm{x}}$ and continued until sunset, indicating that daytime $\mathrm{NO}_{\mathrm{x}}$ production due to on-site use of vehicles was not the main driver for $\Delta \mathrm{O}_{3}$ within the in-tube air.

The role of $\mathrm{NO}_{x}$ chemistry in depleting $\mathrm{O}_{3}$ can be qualitatively estimated by the behavior of $\mathrm{NO} / \mathrm{NO}_{2}$ ratio when the total amount of $\mathrm{NO}_{\mathrm{x}}$ remains stable and without high concentrations of volatile organic compounds. The ratio would decrease if the $\mathrm{NO}+\mathrm{O}_{3}$ reaction proceeds to any substantial extent, otherwise it would increase (Finlayson-Pitts and Pitts, 2000). In Fig. S5, typical daytime $\Delta \mathrm{O}_{3}$ periods $(5,11$ and $14 \mathrm{March})$ are provided, which shows a distinct behavior of $\mathrm{NO}_{\mathrm{x}}$ chemistry: the $\mathrm{NO} / \mathrm{NO}_{2}$ ratio increased on 5 and 14 March whereas it decreased on 11 March, while $\mathrm{NO}_{\mathrm{x}}$ concentration stayed at a relative stable level during the daytime $\Delta \mathrm{O}_{3}$ span. Although based on the experimental design, $\Delta \mathrm{O}_{3}$ obtained by comparisons should not be affected by $\mathrm{NO}_{\mathrm{x}}$ in the background ambient air. If we assume $\mathrm{NO}_{\mathrm{x}}$ chemistry-driven $\mathrm{O}_{3}$ depleting process does contribute to $\Delta \mathrm{O}_{3}$ within the in-tube air, the contribution from $\mathrm{NO}_{\mathrm{x}}$ chemistry in causing $\Delta \mathrm{O}_{3}$ would be expected on 11 March and some other processes (e.g., Br chemistry) would have contributed to $\Delta \mathrm{O}_{3}$ on 5 and 14 March. Such examinations are carried out on each daytime $\Delta \mathrm{O}_{3}$ period when $\mathrm{NO}_{\mathrm{x}}$ measurements were available (3 to $16 \mathrm{March}$ ), and the potential $\mathrm{NO}_{\mathrm{x}}$ contribution (decreasing $\mathrm{NO} / \mathrm{NO}_{2}$ ratio) was only observed on 3 and 11 March.

Furthermore, when we compare $\mathrm{O}_{3}$ between the UV-transmitting and UV-blocking tubes, we consider both in-tube air masses are similar and background $\mathrm{NO}_{\mathrm{x}}$ would affect both to a similar extent whereas the only variable being examined is the UV radiation. Thus, $\mathrm{NO}_{\mathrm{x}}$ photochemistry, initiated by UV radiation, might contribute to $\Delta \mathrm{O}_{3}$ between two tubes. This influence, if possible, is expected to occur throughout the arcylic tube and regardless of the sea ice presence. Not observing a universal $\Delta \mathrm{O}_{3}$ throughout the acrylic tube (Fig. 5) or above the water surface (Fig. 8) indicates $\mathrm{NO}_{\mathrm{x}}$ chemistry plays a minor role in $\Delta \mathrm{O}_{3}$ between two tubes as well.

In conclusion, ambient $\mathrm{O}_{3}$ dynamics is associated with $\mathrm{NO}$ concentrations, especially when ambient $\mathrm{O}_{3}$ depletions during night were observed with $\mathrm{NO}$ peaks (Fig. S3). However, $\Delta \mathrm{O}_{3}$ obtained from comparisons should not be attributed to variations of $\mathrm{NO}_{\mathrm{x}}$ in the background ambient air by the experimental design and the in-situ $\mathrm{NO}_{\mathrm{x}}$ production via snowpack photochemistry is considered negligible. Thus, $\mathrm{NO}_{\mathrm{x}}$ produced either from the urban signal or snowpack photochemistry has limited influence on the $\Delta \mathrm{O}_{3}$ obtained from comparisons. Since the 
general diurnal pattern of $\Delta \mathrm{O}_{3}$ within the in-tube air cannot be explained by $\mathrm{NO}_{\mathrm{x}}$ chemistry, we believe $\mathrm{Br}$ chemistry is most likely the main driver for $\Delta \mathrm{O}_{3}$ reported in this study.

\section{Reference:}

Finlayson-Pitts, B. J., and Pitts Jr, J. N.: Chemistry of the Upper and Lower Atmosphere: Theory, Experiments, and Applications. Elsevier, https://doi.org/10.1016/B978-0-12-2570605.X5000-X, 2000.

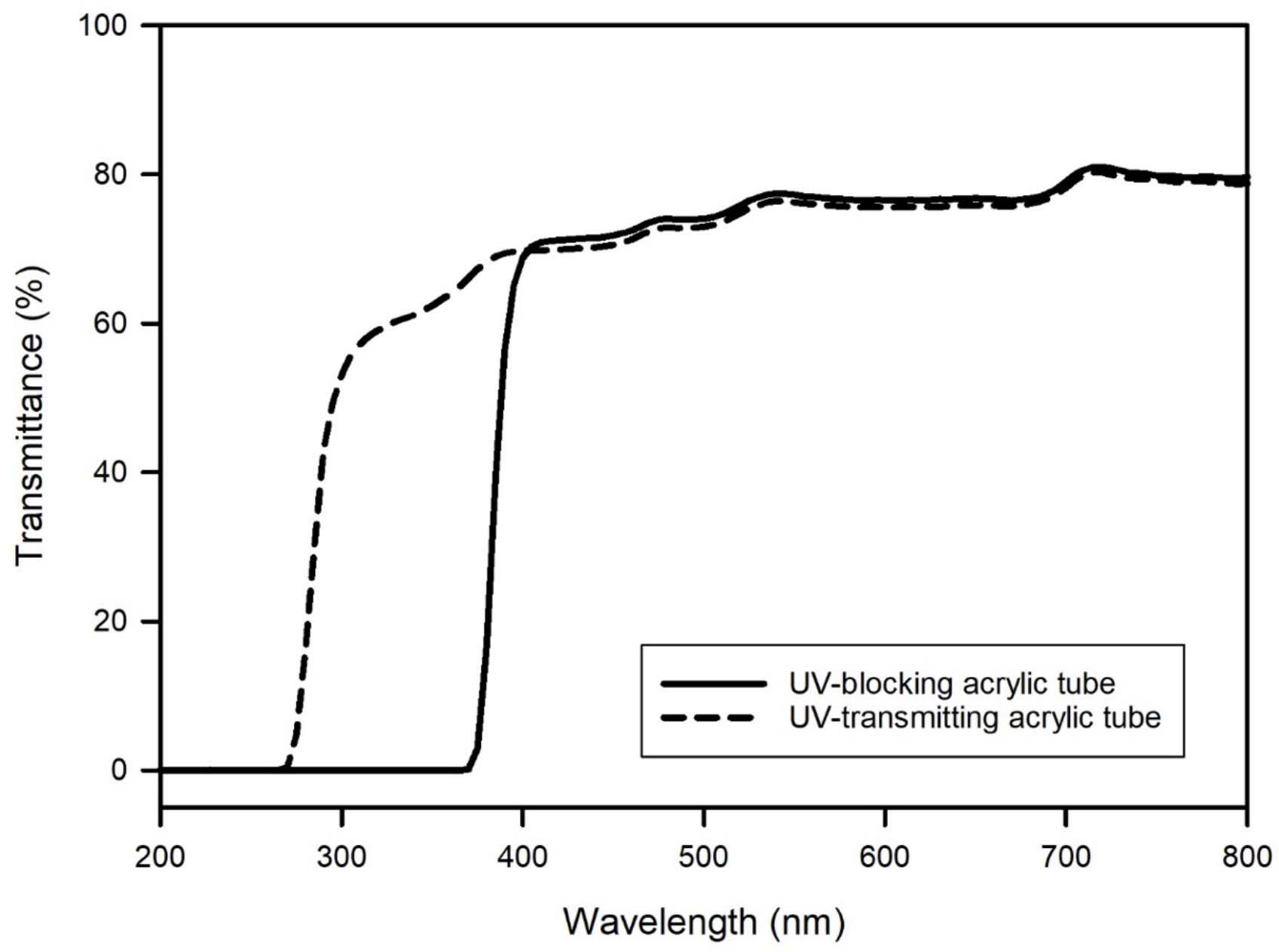

Figure S1. Light transmittance of the two acrylic tubes used in the experiments. 


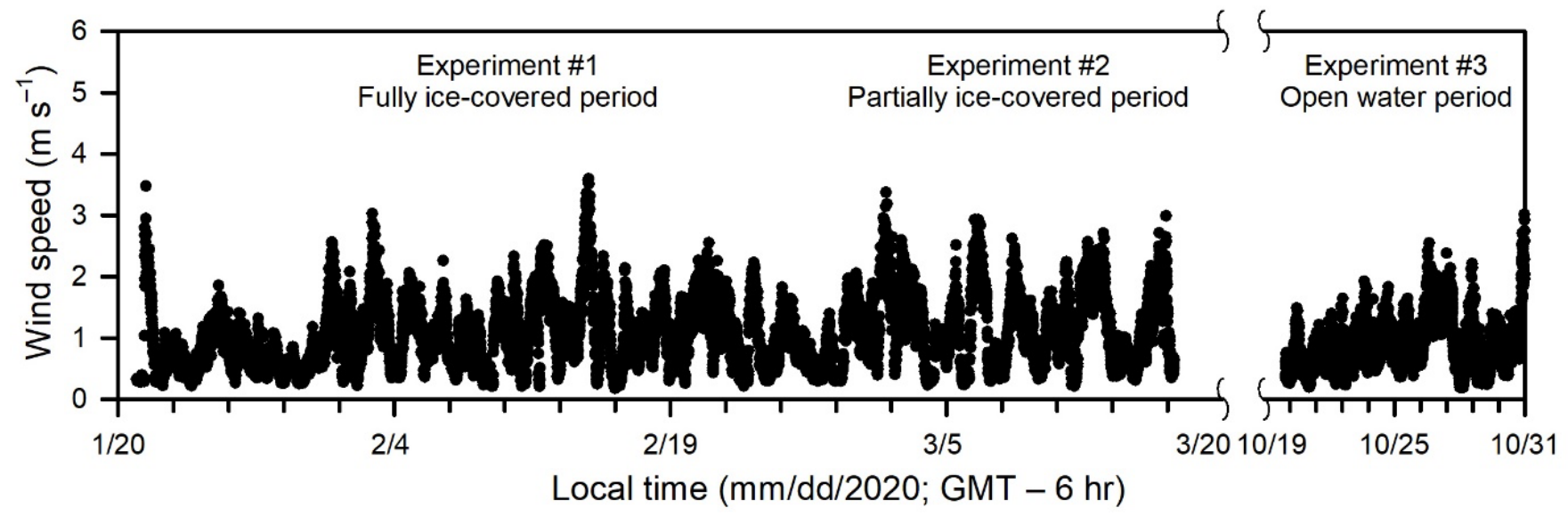

Figure S2. Temporal changes of wind speed measured at $1.5 \mathrm{~m}$ above the ice surface. 

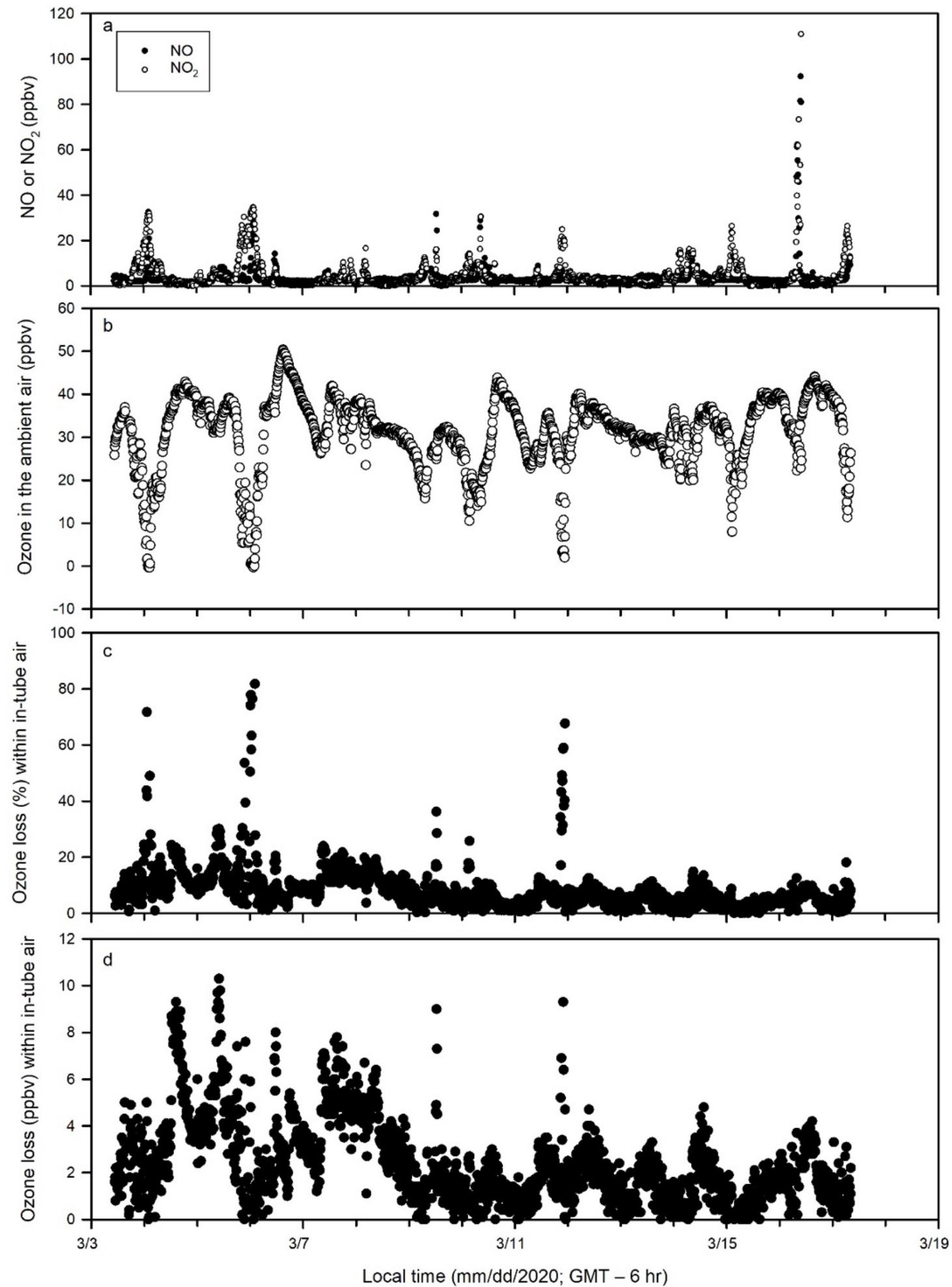

Figure S3. Temporal changes of a) $\mathrm{NO}_{\mathrm{x}}\left(\mathrm{NO}+\mathrm{NO}_{2}\right)$ in the ambient air, b) ozone in the ambient air, c) ozone loss $(\%)$, and d) ozone loss (ppbv) (measured as the difference between the ambient air and in-tube air) during Experiment \#2. 

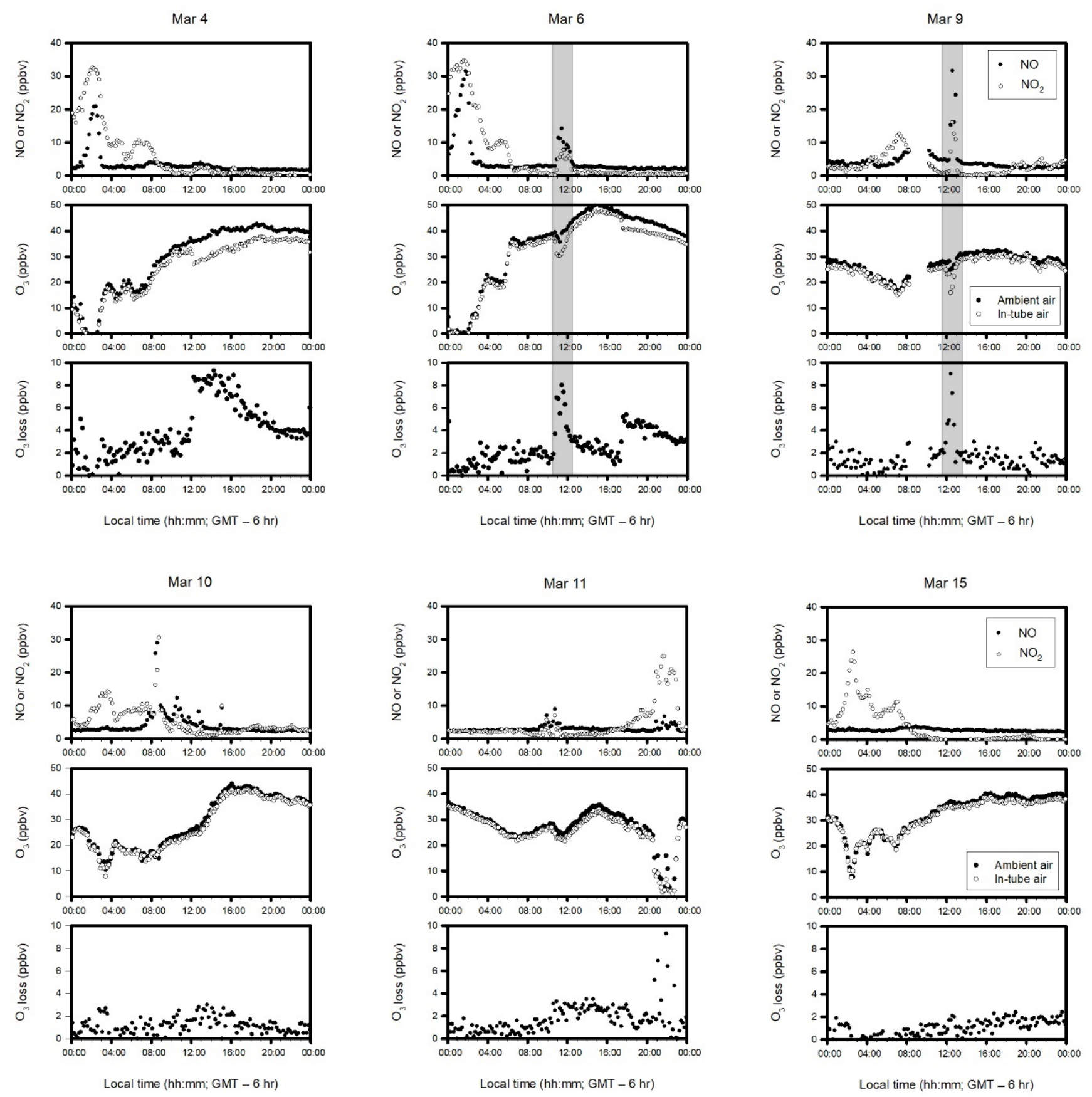

Figure S4. Temporal changes of $\mathrm{O}_{3}, \mathrm{NO}, \mathrm{NO}_{2}$, and $\mathrm{O}_{3}$ loss within the in-tube air (measured as the difference between the ambient air and in-tube air) during each major ambient $\mathrm{O}_{3}$ depletion event of Experiment \#2. 
Mar 5
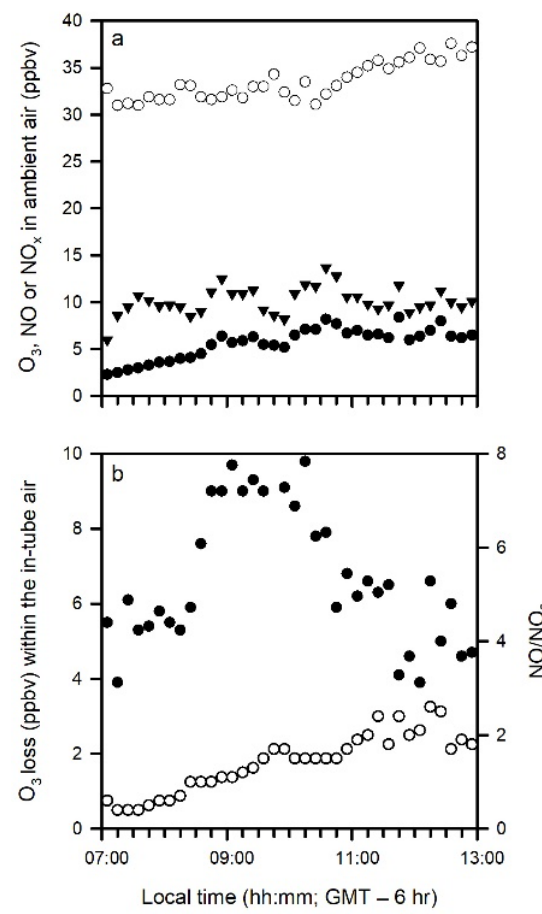

Mar 11
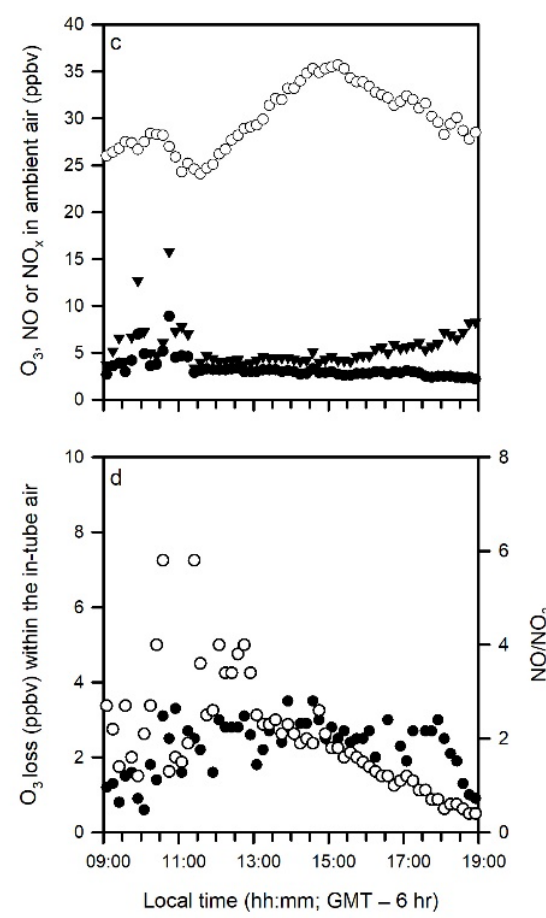

Mar 14
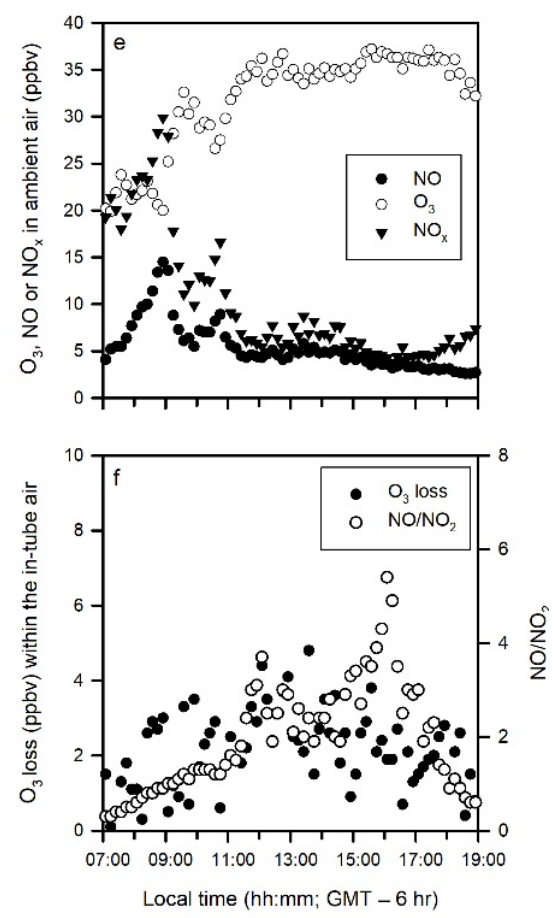

Figure S5. Temporal changes of ambient $\mathrm{O}_{3}, \mathrm{NO}, \mathrm{NO}_{x}$, and $\mathrm{O}_{3}$ loss within the in-tube air (measured as the difference between the ambient air and in-tube air) and $\mathrm{NO} / \mathrm{NO}_{2}$ ratio during the daytime $\mathrm{O}_{3}$ span on 5 March $(\mathrm{a}, \mathrm{b}), 11$ March (c, d), and 14 March (e, f). 

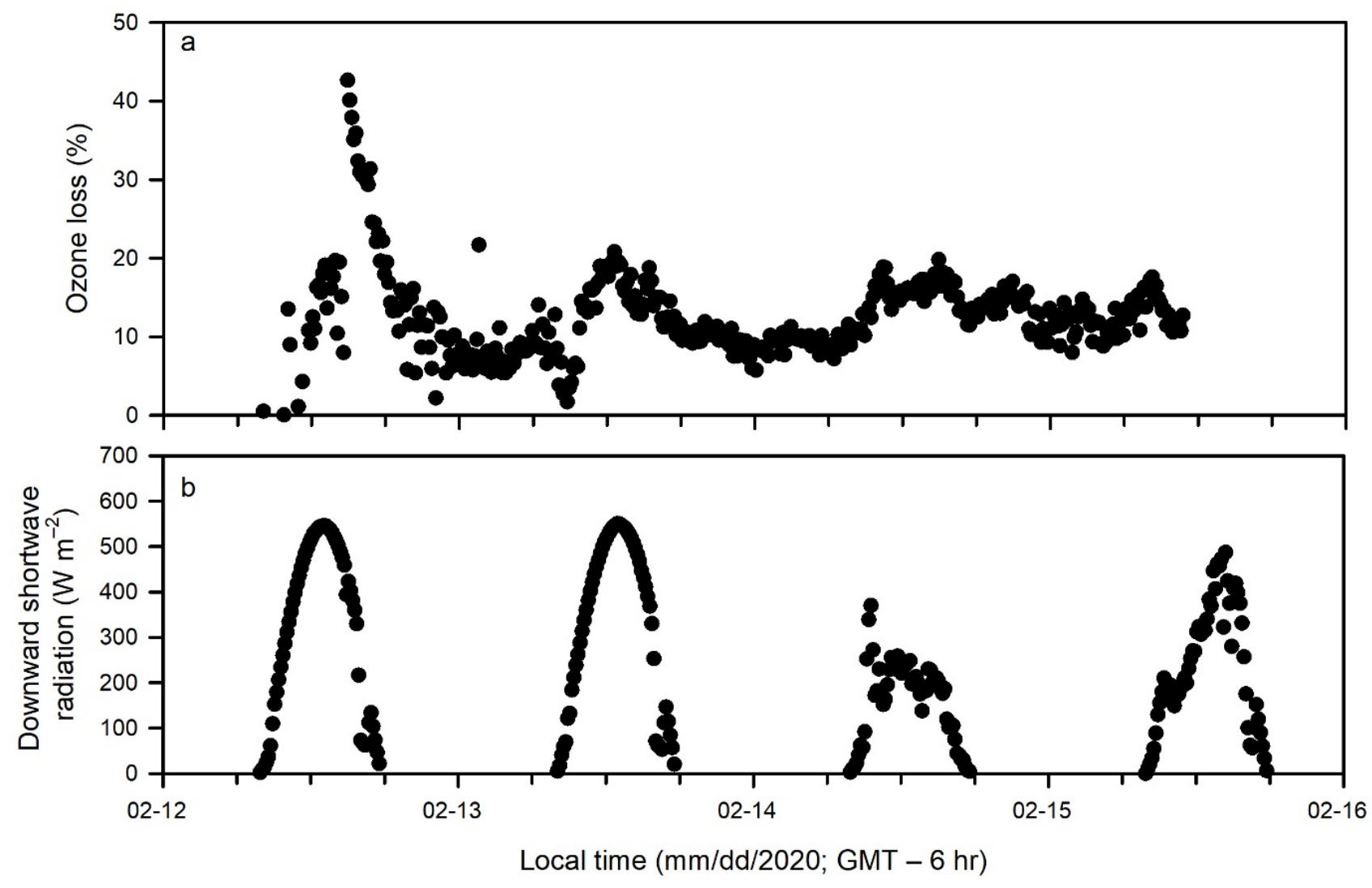

Figure S6. Temporal changes of a) ozone loss (\%) between the UV-transmitting and UV-blocking tubes, and b) downward shortwave radiation during Experiment \#1. 